\title{
In vitro percutaneous penetration and characterization of silver from silver-containing textiles
}

This article was published in the following Dove Press journal:

International Journal of Nanomedicine

10 March 2015

Number of times this article has been viewed

\author{
Carlotta Bianco' \\ Sanja Kezic ${ }^{2}$ \\ Matteo Crosera' \\ Vesna Svetličić ${ }^{3}$ \\ Suzana Šegota ${ }^{3}$ \\ Giovanni Maina ${ }^{4}$ \\ Canzio Romano 5 \\ Francesca Larese (6,7 $^{6}$ \\ Gianpiero Adami' \\ 'Department of Chemical and \\ Pharmaceutical Sciences, University \\ of Trieste, Trieste, Italy; ${ }^{2}$ Academic \\ Medical Center, Coronel Institute, \\ University of Amsterdam, Amsterdam, \\ the Netherlands; ${ }^{3}$ Laboratory for \\ Bioelectrochemistry and Surface \\ Imaging, Division for Marine and \\ Environmental Research, Ruđer \\ Bošković Institute, Zagreb, Croatia; \\ ${ }^{4}$ Department of Clinical and Biological \\ Sciences, University of Turin, Turin, \\ Italy; ${ }^{5}$ Department of Public and \\ Pediatric Health Sciences, University \\ of Turin, Turin, Italy; ${ }^{6}$ Unit of \\ Occupational Medicine, University of \\ Trieste, Trieste, Italy; ${ }^{7}$ Department of \\ Medical Sciences, University of Trieste, \\ Trieste, Italy
}

Correspondence: Carlotta Bianco Department of Chemical and Pharmaceutical Sciences, University of Trieste, Via Giorgeri I, Trieste I-34I 27, Italy

Tel +39040558 3944

Email carlotta_bianco@yahoo.it
Abstract: The objective of this study was to determine the in vitro percutaneous penetration of silver and characterize the silver species released from textiles in different layers of full thickness human skin. For this purpose, two different wound dressings and a garment soaked in artificial sweat were placed in the donor compartments of Franz cells for 24 hours. The concentration of silver in the donor phase and in the skin was determined by an electrothermal atomic absorption spectrometer (ET-AAS) and by inductively coupled plasma mass spectrometer (ICP-MS). The characterization of silver species in the textiles and in the skin layers was made by scanning electron microscopy with integrated energy dispersive X-ray spectroscopy (SEM-EDX). Additionally, the size distribution of silver nanoparticles in the textiles was performed by atomic force microscopy (AFM). On the surface of all investigated materials, silver nanoparticles of different size and morphology were found. Released silver concentrations in the soaking solutions (ie, exposure concentration) ranged from 0.7 to $4.7 \mu \mathrm{g} / \mathrm{mL}(0.6-4.0 \mu \mathrm{g} /$ $\mathrm{cm}^{2}$ ), fitting the bactericidal range. Silver and silver chloride aggregates at sizes of up to $1 \mu \mathrm{m}$ were identified both in the epidermis and dermis. The large size of these particles suggests that the aggregation occurred in the skin. The formation of these aggregates likely slowed down the systemic absorption of silver. Conversely, these aggregates may form a reservoir enabling prolonged release of silver ions, which might lead to local effects.

Keywords: silver textile, silver release, skin

\section{Introduction}

Silver-containing textiles and wound dressings are commonly used in sportswear and for the treatment of burned and infected skin, eg, in patients suffering from atopic eczema. The importance of silver as an antimicrobial agent has been known for centuries and its use has recently increased with the advent of silver nanoparticles. ${ }^{1,2}$ The versatility offered by nanoparticles on different substrates at a limited cost and the peculiarity silver has in avoiding bacterial resistance mechanisms have led to wide application of silver nanoparticles in different biomedical devices. ${ }^{3,4}$ Silver nanoparticles have a large surface area, resulting in a larger amount of silver ions being released and potentially penetrating into and across the skin, particularly if the skin is not intact. ${ }^{5}$ This raises concerns that dermal exposure of larger areas of damaged skin may lead to systemic adverse health effects. ${ }^{6,7}$ In order to carry out a health-risk assessment, it is not only important to quantify and characterize the silver species which are released from a silver-containing material, but also to determine and characterize silver species that penetrate into the skin. Most commercially available products containing silver have no quantitative or qualitative data as to the presence of silver in the material, in particular, details on its release when in contact with the skin. 
Therefore, the characterization of silver species released from these materials under "an in-use scenario" is the first step for the risk assessment process. There is a paucity of data on the silver percutaneous penetration of silver-containing products. ${ }^{8}$ Although percutaneous penetration of silver nanoparticles has long been under debate, ${ }^{5,9}$ it still remains to be clarified whether they can penetrate the skin. Most studies have investigated the release of Ag from commercially available nanotextiles in water, reporting that the silver released was either in a dissolved form, as very small nanoparticles $(1-100 \mathrm{~nm})$, or as aggregates of silver chloride particles. ${ }^{10-13}$

Geranio et al have shown that there is a very low level of dissolved Ag for most textiles and that the majority of the particulate Ag released into washing liquids was present as particles $>450 \mathrm{~nm}$ and that only $5 \%-15 \%$ of particles were smaller. ${ }^{14}$ In contrast to what was reported by Geranio et al, Farkas et al have reported that the Ag particulates, which were released into the water of a washing machine, are mostly present as nanoparticles approximately $10 \mathrm{~nm}$ in size. ${ }^{14,15}$ Impellitteri et al demonstrated that the chemical composition of washing solutions strongly affects the speciation of the silver released and that there is a relevant transformation of elemental $\mathrm{Ag}$ to $\mathrm{AgCl}$ in the presence of chlorides. ${ }^{16}$ Furthermore, Kulthong et al showed that silver release was likely to be dependent on the amount of silver deposed on the fibers, the fabric quality, and the artificial sweat formulations, including its $\mathrm{pH} .{ }^{17}$

In this study, quantitative and qualitative silver release from three biomedical materials used for topical application have been assessed. Furthermore, in vitro percutaneous penetration and silver speciation in different skin layers have been determined.

\section{Materials and methods Chemicals}

All the chemicals used were of analytical grade. Urea, lactic acid, sodium chloride, sodium hydrogen phosphate, potassium dihydrogen phosphate, nitric acid (69\% volume per volume $[\mathrm{v} / \mathrm{v}])$ and hydrochloric acid (36.5\%-38\% v/v), were purchased from Sigma-Aldrich Co. (St Louis, MO, USA) and ammonium hydroxide (25\%) from JT Baker (Center Valley, PA, USA). Ultrapure water was produced with a Millipore purification pack system (Milli-Q ${ }^{\circledR}$ water; EMD Millipore, Billerica, MA, USA).

\section{Silver-containing textiles}

Three different materials that are used for their antimicrobial properties were investigated. Material 1 is one of the most commonly used medical devices that contain silver nanoparticles (Acticoat ${ }^{\mathrm{TM}}$ ). High-density polyethylene mesh with a core of rayon and polyester is coated with nanocrystalline silver. ${ }^{18}$ The manufacturer declares an antimicrobial effect that will last for 3 days, which is the maximum recommended application time. Material 2 is a wound dressing composed of nylon-spandex fibers plated with $20 \%$ (by mass) metallic silver by an electroless deposition process. The antimicrobial barrier properties of this material have been evaluated by Krieger et al and Silver et al. ${ }^{19,20}$

Material 3 contains 79\% modal, 11\% polyamide, 7\% spandex, and 3\% silver plated by an electroless deposition process (according to the producer's declarations). Amongst the investigated materials, only material 1 declares the presence of silver nanoparticles.

\section{Determination of silver in the materials}

Three samples $\left(1 \mathrm{~cm}^{2}\right)$ of each material were dissolved in $5 \mathrm{~mL}$ of nitric acid $69 \% \mathrm{v} / \mathrm{v}$, ensuring that the material was completely covered by the liquid. After 24 hours, the resulting solutions were diluted to $50 \mathrm{~mL}$ with Milli-Q water and analyzed for silver content by inductively coupled plasmaatomic emission spectroscopy (ICP-AES).

\section{In vitro test}

The experiment was performed using human cryopreserved skin. The skin from the back and arms of two donors (26 and 68 years) was cryopreserved immediately after surgical removal, according to the protocol patented by the Skin Bank at the CTO hospital in Turin. ${ }^{21}$ Each piece of skin was clamped between the donor and the receptor compartment; the exposed skin area was $1.77 \mathrm{~cm}^{2}$ and the average skin thickness was $1 \mathrm{~mm}$ (percentage relative error of $1 \%$ and repeatability expressed as relative standard deviation [RSD] of 5\%). Skin integrity was assessed using electrical conductibility before and after the experiment as previously described, cells with a resistance $<3.95 \pm 0.27 \mathrm{k} \Omega \mathrm{cm}^{-2}$ were considered to be damaged and rejected as suggested by Bianco et al and Davies et al. ${ }^{22,23}$

Percutaneous penetration was investigated using static diffusion cells according to the Franz method. ${ }^{24}$ Each donor chamber was filled with $1.5 \mathrm{~mL}$ of synthetic sweat (Milli-Q water, $0.5 \% \mathrm{NaCl}, 0.1 \%$ lactic acid, and $0.1 \%$ urea, with ammonium hydroxide to reach a $\mathrm{pH}$ of 4.5 ) in which a sample of silver material $\left(1.77 \mathrm{~cm}^{2}\right)$ was soaked. Six chambers were prepared for each material tested (two donors, three samples per donor), while two donor chambers were filled with synthetic sweat as a blank. The total silver concentration of each 
donor phase was determined by inductively coupled plasma mass spectrometer (ICP-MS).

The receptor compartment had a volume of $12.0 \mathrm{~mL}$ and was maintained at $+32^{\circ} \mathrm{C}$ by the circulation of thermostated water in the jacket that surrounds the cell. The physiological solution used as the receptor fluid was prepared by dissolving $2.38 \mathrm{~g}$ of $\mathrm{Na}_{2} \mathrm{HPO}_{4}, 0.19 \mathrm{~g}$ of $\mathrm{KH}_{2} \mathrm{PO}_{4}$, and $9 \mathrm{~g}$ of $\mathrm{NaCl}$ in $1 \mathrm{~L}$ of Milli-Q water (final $\mathrm{pH}=7.4$ ). The concentration of the salt in the receptor fluid was approximately the same as that present in blood. The solution in each cell was continuously stirred using a Teflon-coated magnetic stirrer.

At selected intervals, 2, 4, 8, 16, and 24 hours, $1.5 \mathrm{~mL}$ of the samples of the receptor solution were collected for silver analysis. Each receptor sample was immediately replaced with an equal volume of fresh physiological solution.

\section{Skin sample preparation for analysis}

At the end of the 24-hour penetration test, the skin was washed with a physiological solution to remove any excess silver from the surface. Among the three replicates from each donor, two of them were separated into dermis and epidermis by heat shock by immerging them in $+60^{\circ} \mathrm{C}$ water for 1 minute. Subsequently, they were placed into a drying oven for 24 hours and put into glass tubes with $1 \mathrm{~mL}$ of $\mathrm{HNO}_{3} 69 \% \mathrm{v} / \mathrm{v}$ for digestion. The resulting solutions were diluted with Milli-Q water for ICP-MS analysis. The third replicate from each donor was divided into two subsamples: the first was dried and digested as previously described for the analysis of total silver; the second was fixed with $10 \%$ glutaraldehyde, washed with ethanol-water solutions with increasing concentrations of ethanol, and then stored in ethanol at 98\%, until scanning electron microscopy (SEM) analysis.

\section{Instrumental analysis}

Scanning electron microscopy with integrated energy dispersive X-ray spectroscopy (SEM-EDX) analysis was performed using a Hitachi model (TM-3000) equipped with Oxford Instruments X-ray Microanalysis (Hitachi Ltd., Tokyo, Japan).

The total silver concentration in the solutions from the materials' dissolution were tested by means of ICP-AES using a Spectroflame Modula E optical plasma interface (OPI) instrument (Spectro Analytical Instruments $\mathrm{GmbH}$, Kleve, Germany). The samples were analyzed by measuring against standard solutions for instrumental calibration (range $0-10 \mu \mathrm{g} / \mathrm{L}$ ). The limit of detection (LOD) at the operative wavelength of $328.068 \mathrm{~nm}$ was $0.05 \mu \mathrm{g} / \mathrm{L}$. The precision of the measurements (repeatability) was expressed as RSD\% that was always $<5 \%$.

The total silver concentration in the receptor fluid was determined by an ICP-MS 7500 CE (Agilent Technologies, Santa Clara, CA, USA) with an integrated autosampler. The selected ion mass was 107 atomic mass units. The limit of silver detection was $0.05 \mu \mathrm{g} / \mathrm{L}$ (standard solutions: $0.1,0.5,1.0,5.0,10.0 \mu \mathrm{g} / \mathrm{L} ; \mathrm{RSD} \%$ for the analysis was always $<5 \%$ ). The accuracy was determined by analyzing National Institute of Standards and Technology (NIST)certified reference material 1640-a (trace elements in natural water); the analyzed results are within the range of the certified value $(8.081 \pm 0.046) \mu \mathrm{g} / \mathrm{L}$.

The silver content in the skin and in the donor liquid was measured by an electrothermal atomic absorption spectrometer (ET-AAS; model 4100 ZL; Perkin Elmer Inc., Waltham, MA, USA) with AS/71 autosampler and transversely heated graphite atomizer (THGA) with Zeeman background correction (LOD: $0.5 \mu \mathrm{g} / \mathrm{L}$; standard solutions: 5.0, 25.0, $50.0 \mu \mathrm{g} / \mathrm{L})$.

The atomic force microscopy (AFM) analysis of silver particles on the surface of the material was performed using a Multimode AFM with Nanoscope IIIa controller (Bruker Corporation, Billerica, MA, USA) with a vertical engagement (JV) $125 \mu \mathrm{m}$ scanner. Contact mode was used throughout the experiments, using silicon-nitride tips (NP-20, Bruker, nominal frequency $56 \mathrm{kHz}$, nominal spring constant of $0.32 \mathrm{~N} / \mathrm{m}$ ) and a scan resolution of 512 samples per line. The processing and analysis of images was done by NanoScope ${ }^{\mathrm{TM}}$ software (version V614r1; Digital Instruments, Tonawanda, NY, USA). A previously developed protocol was used for textile fabric AFM imaging. ${ }^{25}$ Samples of silver material $\left(1 \mathrm{~cm}^{2}\right)$ were fixed onto the sample holder (stainless steel, diameter $1.5 \mathrm{~mm}$ ) immediately before testing. All measurements were performed under ambient conditions, ie, at room temperature and with a relative air humidity of $50 \%-60 \%$. The sample surface areas investigated ranged from $25 \mu \mathrm{m} \times 25 \mu \mathrm{m}$ to $2 \mu \mathrm{m} \times 2 \mu \mathrm{m}$, so as to ensure that the scan areas of $2 \mu \mathrm{m} \times 2 \mu \mathrm{m}$ were representative of the features of the material of interest.

\section{Data analysis}

Data analysis was performed using SPSS software (v20 for Windows; IBM Corporation, Armonk, NY, USA). The difference between independent data was assessed by means of one-way analysis of variance (ANOVA) tests. A $P$-value of 0.05 was considered as the limit of statistical significance. 


\section{Results}

\section{Content of silver in the textiles}

The amount of silver in the investigated materials is shown in Table 1. The digestion of the textiles with nitric acid as described in the 'Experimental' section resulted in transparent and homogeneous solutions. The silver concentration in the textiles reported in Table 1 are expressed as mg of silver per surface area and as a percentage of silver in the textile (weight/weight [w/w]). It should be highlighted that material 1 has a higher mass per surface area than materials 2 and 3 . Thus, the expression of silver concentration per surface unit is more representative for the silver dose, ie, the amount of silver in contact with the skin. The silver content of the three materials $\left(\mu \mathrm{g} / \mathrm{cm}^{2}\right)$ was compared by means of an one-way ANOVA test revealing significant differences $(P<0.05)$. As shown in Table 1 , the content of silver in the textiles follows this trend: material $1>$ material $3>$ material 2 .
Table I The concentration of silver in the textile and in donor chambers after 24 hours of soaking

\begin{tabular}{llll}
\hline Ag concentration & $\begin{array}{l}\text { Material I } \\
\text { mean } \pm \text { SD }\end{array}$ & $\begin{array}{l}\text { Material 2 } \\
\text { mean } \pm \text { SD }\end{array}$ & $\begin{array}{l}\text { Material 3 } \\
\text { mean } \pm \text { SD }\end{array}$ \\
\hline Textile $\left(\mathrm{mg} / \mathrm{cm}^{2}\right)$ & $1.37 \pm 0.05$ & $0.33 \pm 0.05$ & $0.67 \pm 0.09$ \\
Textile $(\% \mathrm{w} / \mathrm{w})$ & $8.1 \pm 1.3$ & $7.1 \pm 0.2$ & $3.6 \pm 0.1$ \\
Donor fluid $\left(\mu \mathrm{g} / \mathrm{cm}^{2}\right)$ & $4.0 \pm 1.6$ & $0.6 \pm 0.1$ & $1.8 \pm 0.1$ \\
Donor fluid $(\mu \mathrm{g} / \mathrm{mL})$ & $4.7 \pm 1.9$ & $0.7 \pm 0.1$ & $2.2 \pm 0.1$ \\
\hline
\end{tabular}

Abbreviations: SD, standard deviation; w/w, weight per weight.

\section{Characterization of silver particles in the investigated textiles before the release test}

Material 1 is made of a silver nanocrystal grid enveloped by gauze. The SEM analysis was performed only on the gauze (Figure 1). The analysis of particles on the grid surface was not possible due to its electron density. However, we analyzed the grid with AFM, which has a better resolution and is

A

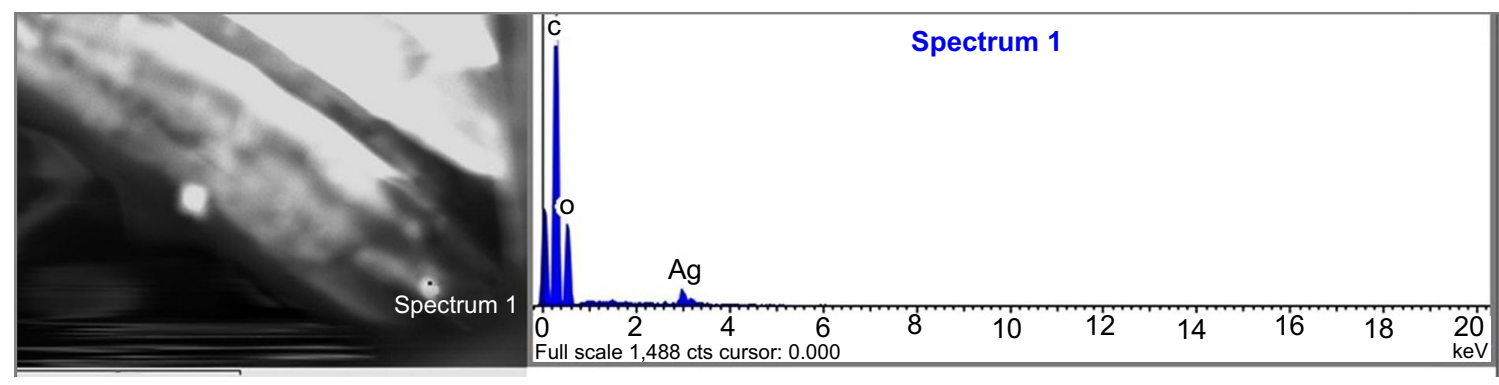

$5 \mu \mathrm{m}$

B

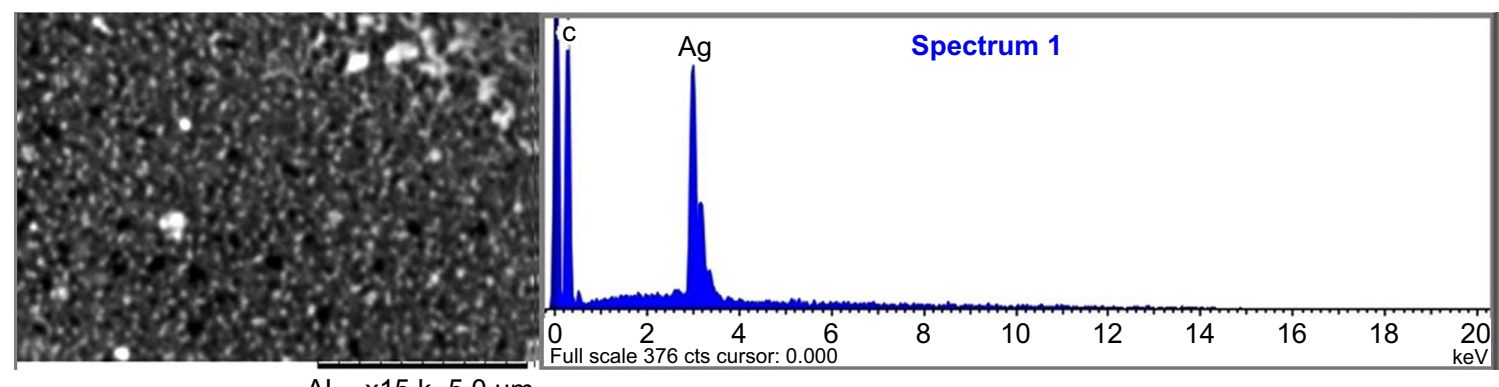

AL $\times 15 \mathrm{k} 5.0 \mu \mathrm{m}$
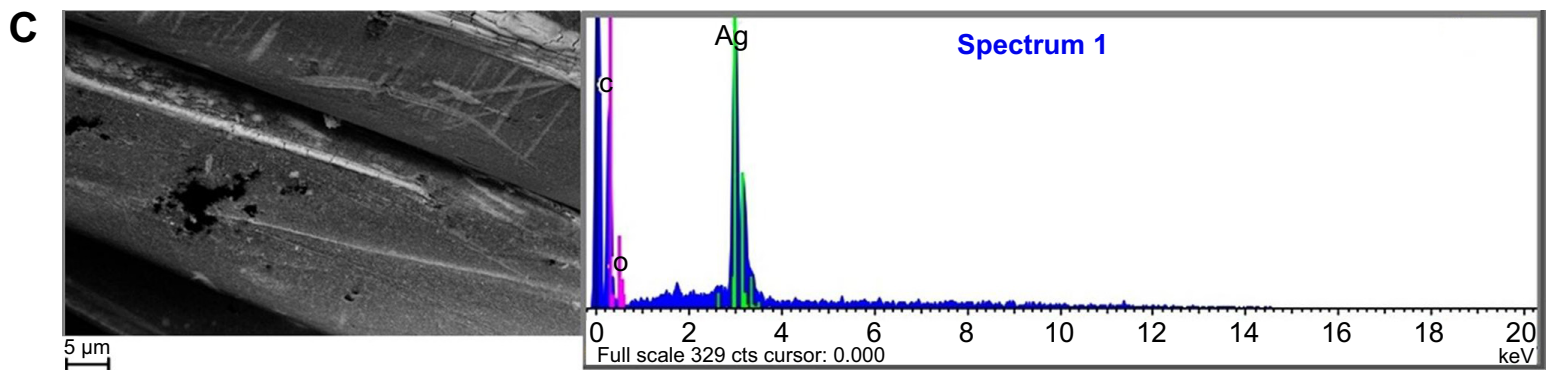

Figure I SEM-EDX images of silver containing textiles analyzed before the release test.

Notes: Morphologic and electron image of: (A) material I gauze fiber; (B) material 2; (C) material 3.

Abbreviation: EDX, energy dispersive X-ray spectroscopy; SEM, scanning electron microscopy. 
not influenced by the electron density of the grid (Figure 2). Although the gauze was not expected to contain silver, some micrometric particles of silver were sporadically identified by SEM-EDX. AFM revealed tetrahedron-shaped nanocrystals with an average height of $16 \mathrm{~nm}$. However, crystals of $120 \mathrm{~nm}$ height and $300 \mathrm{~nm}$ width were also observed.

The SEM analysis of material 2 revealed a highly homogeneous nanostructured surface with silver particles ranging from 50 to $200 \mathrm{~nm}$. The AFM analysis was in good agreement with the size distribution of the silver particles detected by SEM. The high-resolution AFM topography on the fibers in material 2 is shown in Figure 2B. The average height of the predominantly cubic-shaped nanocrystals was $36 \mathrm{~nm}$ and crystals of $330 \mathrm{~nm}$ height and $700 \mathrm{~nm}$ width were also sporadically observed.

The SEM morphologic analysis of material 3 (Figure 1C) revealed a mixture of silver-coated and uncoated fibers. The silver-coated fibers were brighter because of the electron density of silver and the coating was not homogeneous on the fiber surfaces. Silver aggregates with a wide dimensional range (300 nm-1 $\mu \mathrm{m})$ were found also on the surface of the uncoated fibers. High-resolution AFM imaging revealed spheroid-shaped particles with a wide size distribution and an average height of $11 \mathrm{~nm}$ (Figure 2C). Some spheroid aggregates reached a height of $130 \mathrm{~nm}$ and a width of $700 \mathrm{~nm}$.

\section{Characterization of silver particles in the textiles after the release test}

After 24 hours of immersion in synthetic sweat, silver-silver chloride aggregates were detected by SEM-EDX on the gauze attached to the silver grid of material 1, as shown in Figure $3 \mathrm{~A}$ (diameter: $1 \mu \mathrm{m}$ ). SEM analysis of material 2 (Figure 3B) detected the presence of silver-silver chloride clusters in a wide range of dimensions. Sodium was also noticed as a component on the surface of the clusters. Silver-silver chloride clusters were also detected on the surface of the uncoated fibers of material 3 (Figure 3C).
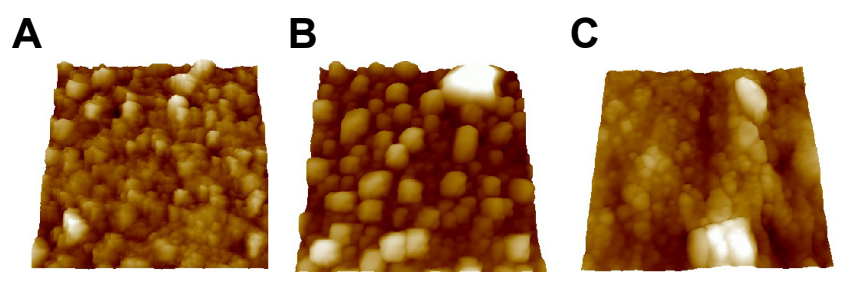

Figure 2 AFM topographic images of silver-containing textiles before the release test: (A) material I silver grid; (B) material 2; (C) material 3.

Notes: Images are presented as 3D height data and are shown on the same scale: scan size of $2 \mu \mathrm{m} \times 2 \mu \mathrm{m}$ and vertical scale of $200 \mathrm{~nm}$.

Abbreviation: AFM, atomic force microscopy.

\section{Percutaneous penetration}

The amount of silver in the donor compartment is given in Table 1 as the exposure dose ( $\mu \mathrm{g}$ of silver per exposed skin area) and as the concentration of silver in the donor solution $(\mu \mathrm{g} / \mathrm{mL})$. The silver concentration in the donor fluid was the highest for material $1(4.7 \pm 1.9 \mu \mathrm{g} / \mathrm{mL})$. This finding is consistent with the highest amount of silver found after acidic digestion of material $1\left(1.37 \pm 0.05 \mathrm{mg} / \mathrm{cm}^{2}\right)$ in comparison with materials 2 and 3 (Table 1). The release of silver in the donor compartment reflects the silver content in the textiles: material $1>$ material $3>$ material 2 . Thus, a higher content of silver in the material results in a higher release of silver into solution.

The silver concentration in the receptor fluid of all diffusion chambers sampled up to 12 hours was below the ICP-MS LOD. Silver was detected in the receptor fluid collected at 20 hours, although the concentrations were just below the ICP-MS limit of quantification (data not shown). At 24 hours, silver was detected in all receptor fluid samples (Table 2)

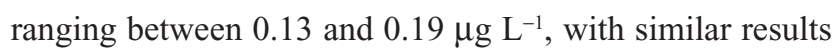
for all investigated materials.

The amount of silver in the epidermis and dermis was considerably higher than in the receptor fluid. Again, the amount of silver found in the epidermis and dermis was the highest for material 1. There was a large difference in the amount of silver between the two donors; this difference was higher in the epidermis than in the dermis.

\section{Characterization of silver particles in the skin}

By using SEM-EDX, we identified the presence of electrondense aggregates of silver and silver chloride with a wide size distribution both in the epidermis and dermis for all investigated materials.

Figure 4 shows representative images obtained by SEMEDX analysis in the three samples. There was a considerable difference in the number of silver aggregates found in the skin of the two donors. The skin of donor 2 had more hair than donor 1 (Figure 5). Consistently, a larger number of silver aggregates was detected on the skin of donor 2 than in donor 1 .

\section{Discussion Characterization of silver in the investigated materials}

The amount of silver in the tested materials varied from $3.6 \%$ to $8.1 \% \mathrm{w} / \mathrm{w}$. As determined by SEM-EDX and AFM, material 1 (Acticoat ${ }^{\mathrm{TM}}$ ) showed a wide size distribution of tetrahedron-shaped nanocrystals. Consistently with our findings, the morphologic variability of the silver aggregates 

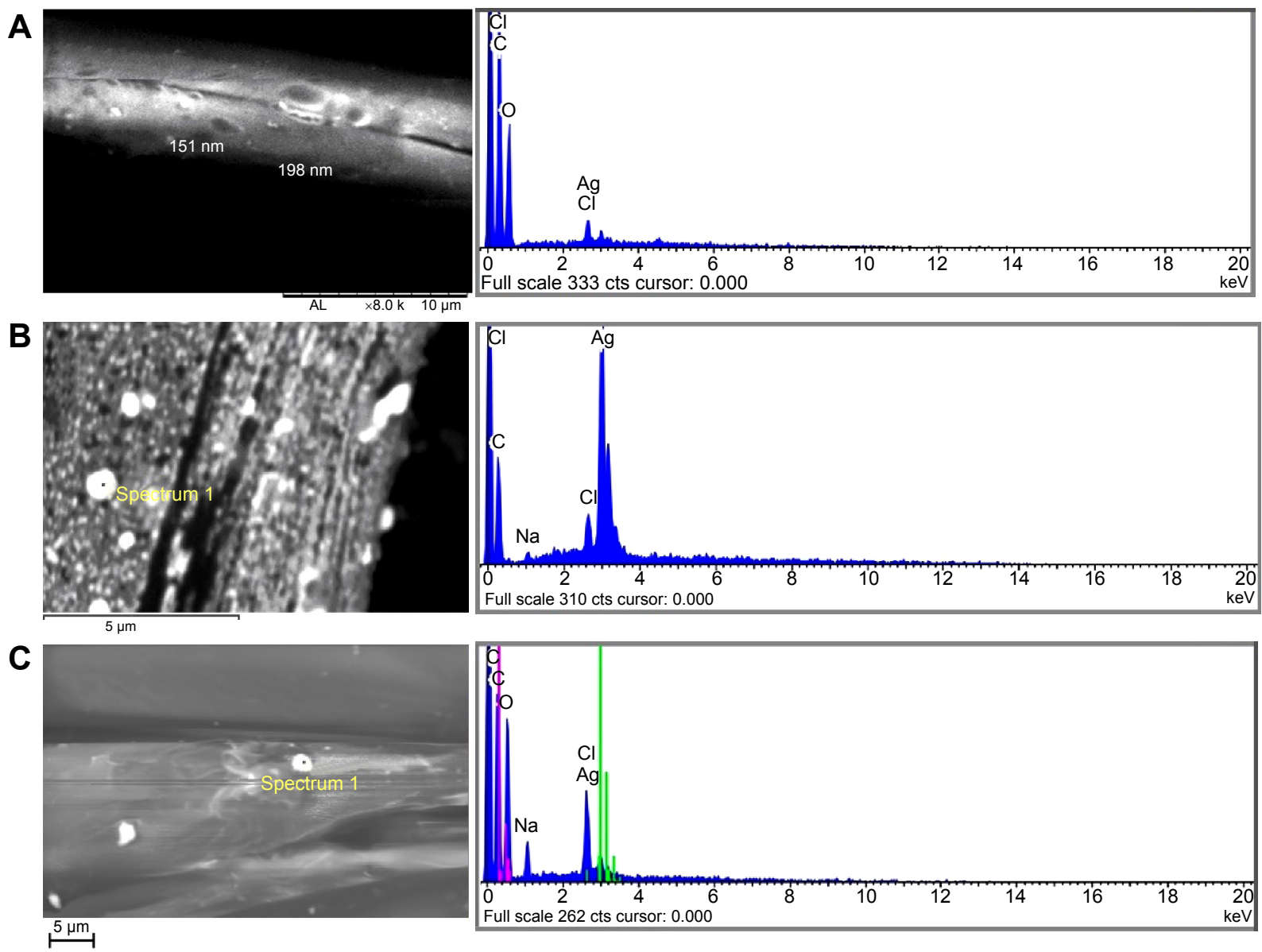

Figure 3 SEM analysis of nanosilver textiles after 24 hours of immersion in synthetic sweat.

Notes: Morphologic and electron image of: (A) material I gauze fiber; (B) material 2; (C) material 3.

Abbreviation: SEM, scanning electron microscopy.

on the surface of the Acticoat was also reported by Rigo et al. ${ }^{26}$ Moreover, the manufacturer declared the possibility of an inhomogeneous coating of the fibers with nanocrystals.

Materials 2 and 3 showed more regular and homogeneous coverage of silver particles (Figure 2). The AFM analysis was in good agreement with the size distribution of the silver particles detected by SEM. It was noted that the presence of a nanostructured covering was only declared for material 1 .

After the 24-hour exposure test, the investigated materials showed electron-dense aggregates on the surface; EDX

Table 2 Silver concentration in the skin layers (median; 25th75 th percentiles) and in receptor compartments (mean \pm SD), after 24 hours of exposure

\begin{tabular}{llll}
\hline Ag concentration & Material I & Material 2 & Material 3 \\
\hline Epidermis $\left(\mu \mathrm{g} / \mathrm{cm}^{2}\right)$ & $\mathrm{I} .05 ; 0.02-3.56$ & $0.26 ; 0.01-0.55$ & $0.33 ; 0.0 \mathrm{I}-0.67$ \\
Dermis $\left(\mu \mathrm{g} / \mathrm{cm}^{2}\right)$ & $0.30 ; 0.0 \mathrm{I}-0.59$ & $0.03 ; 0.003-0.08$ & $0.07 ; 0.0 \mathrm{I}-0.15$ \\
$\operatorname{Receptor}$ fluid & $0.13 \pm 0.08$ & $0.18 \pm 0.09$ & $0.17 \pm 0.1 \mathrm{I}$ \\
$\mathrm{Ag}(\mu \mathrm{g} / \mathrm{L})$ & & & \\
\hline
\end{tabular}

Abbreviation: SD, standard deviation. detected the presence of silver and chlorine as being the major components of these aggregates. This is consistent with previous studies showing that silver is released from textiles mainly as silver ions, which subsequently react with chloride ions from the sweat, forming silver chloride. ${ }^{27}$ As silver chloride is poorly soluble, its precipitation limits the amount of dissolved silver available for penetration.

The AFM and SEM analyses gave comparable results on the size of the silver particles on the material. The combination of these two techniques allows for a characterization of the size and morphology of silver particles which are both related to silver release and, consequently, to the antimicrobial activity. While SEM-EDX provides information on the composition and dimensions of the silver particles and clusters on the $x-y$ plane, AFM shows the three-dimensional profile of the particles found on the fabric surface. Furthermore, the resolution of AFM $(1 \mathrm{~nm})$ is better than that of SEM $(30 \mathrm{~nm})$. 
A
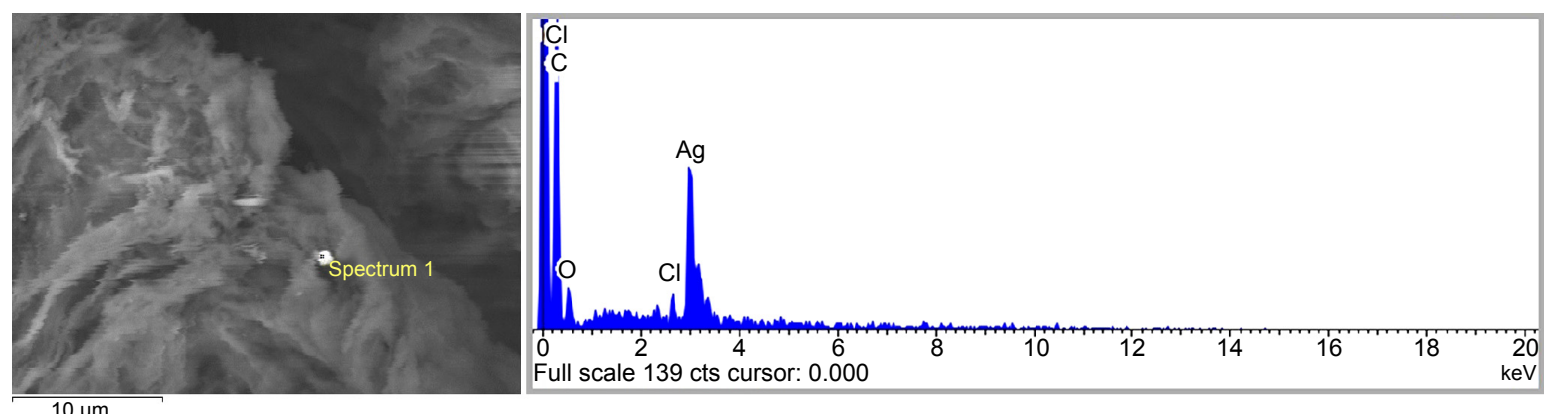

B
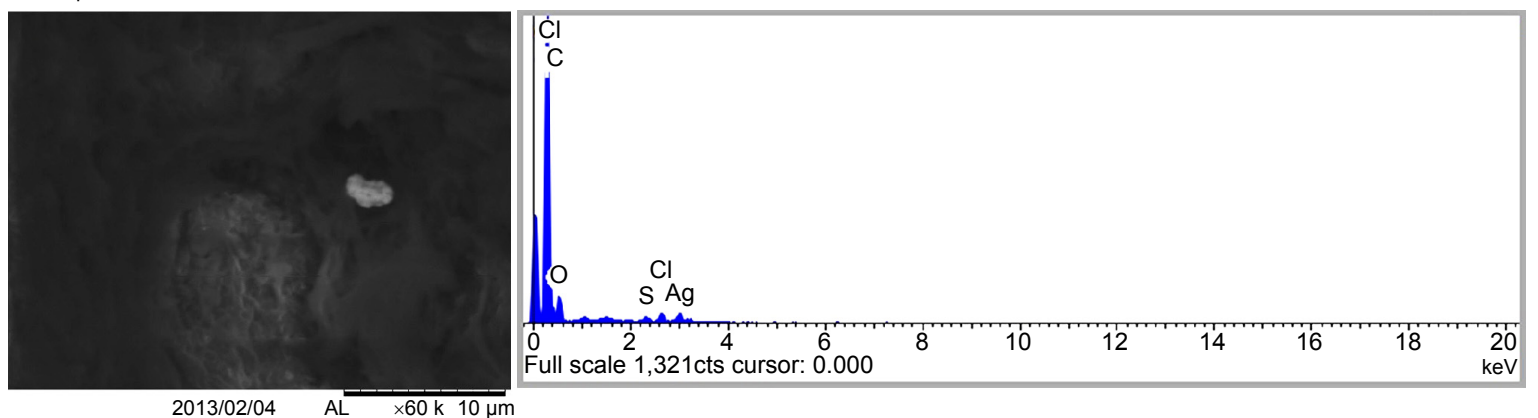

C
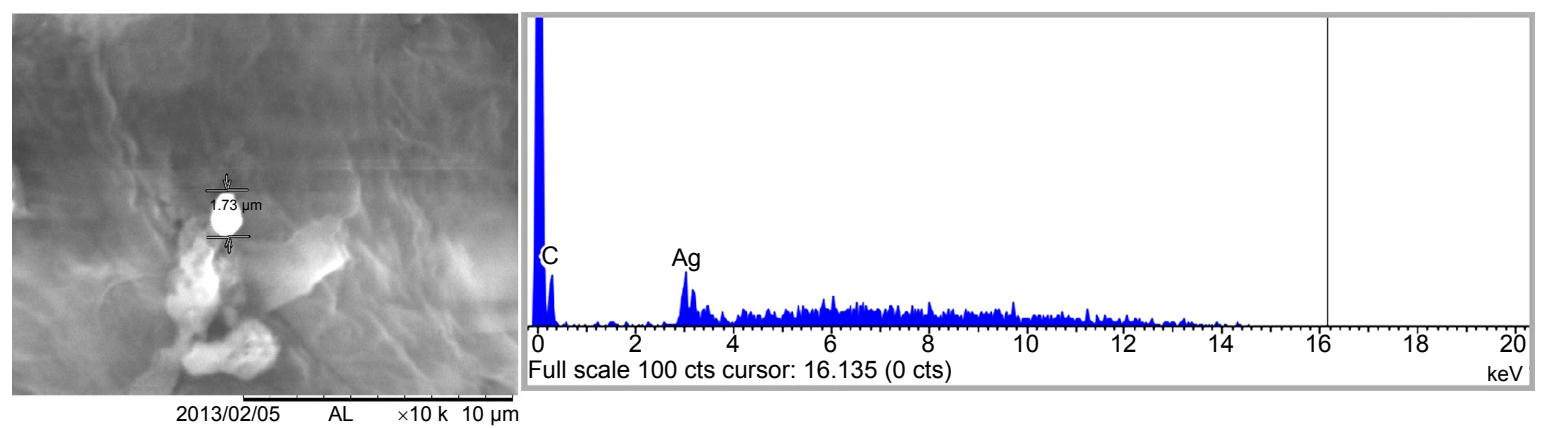

Figure 4 SEM-EDX images of silver particles found in human skin after 24 hours exposure to silver textiles.

Notes: Left: SEM image of silver clusters and in the skin layers: (A) epidermis, material I; (B) dermis, material 2; (C) epidermis, material 3. Right: EDX spectral identification.

Abbreviations: EDX, energy dispersive X-ray spectroscopy; SEM, scanning electron microscopy.

\section{Percutaneous penetration of silver}

The release of silver from the materials, which determines exposure concentration, differed among the three investigated materials and amounted respectively to $4.0,0.6$ and $1.8 \mu \mathrm{g} / \mathrm{cm}^{2}$ (4.7 to 0.7 and $2.1 \mu \mathrm{g} / \mathrm{mL}$ ). The silver released from material 1 was comparable to that found in the study by Rigo et al performed in a saline environment, which amounted to $4.21 \mu \mathrm{g} / \mathrm{g}$ (w/w Ag/saline solution). ${ }^{26}$ An interesting review of Brett et al reported that silver concentration of about $1 \mathrm{mg} / \mathrm{L}$ shows bactericidal properties. Otherwise Greulich et al reported that the minimum inhibitory concentration (MIC) of silver against Staphylococcus aureus is in the range $2.5-5 \mathrm{mg} / \mathrm{L}$ (depending on the inoculated cell number of bacteria). ${ }^{28,29}$ Thus, the silver amount released by the three materials tested in this study is in the bactericidal range.

Silver could reliably be quantified (ie, concentration above the limit of quantification) only in the samples of receptor fluids collected after 24 hours of exposure, suggesting low systemic absorption. However, the levels of silver in the epidermis and dermis were considerably higher than in the receptor fluid, revealing that silver is able to penetrate across the stratum corneum (SC), which is the principle barrier of the skin. Low concentrations of silver in the receptor fluid might at least partly be explained by the formation of aggregates in the epidermis and dermis, which slows down their further penetration. In the present study, we preferred the full thickness skin above dermatomed skin as we also wanted to characterize the silver particles in the deeper skin layers. Likely, if dermatomed skin was used, the penetration of silver into the receptor fluid might have been higher. The large dimensions of the silver-silver chloride aggregates detected in the dermis suggest that silver chloride precipitation and silver particle aggregation occurred in the deeper layers of the skin, as the aggregates of this size cannot penetrate across the SC. Consistently with our findings, van der Zande et al found in an in vivo 


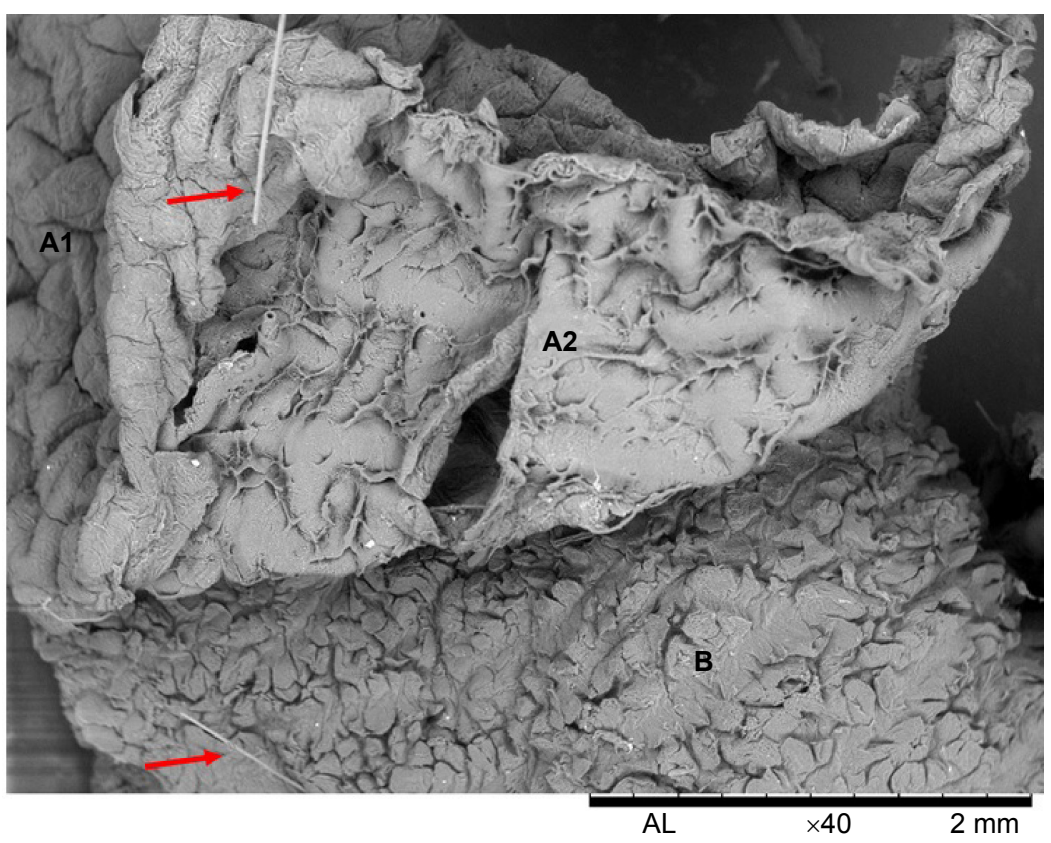

Figure 5 SEM image of skin from donor 2 showing hair (red arrows), epidermis (AI: upper; A2: lower), and dermis (B).

Notes: The white spots are micrometric aggregates of silver. The skin was exposed to material 3 for 24 hours.

Abbreviation: SEM, scanning electron microscopy.

study in rats that silver-containing particles, presumably composed of silver salts, can be formed from silver ions. ${ }^{30}$ The silver-containing particles $(>20 \mathrm{~nm}$ ) were found in the liver, spleen, lungs, and in the gastrointestinal contents after exposition to both silver nanoparticles $(<20 \mathrm{~nm})$ and silver nitrate. Moreover, George et al found silver aggregates $(750 \mathrm{~nm})$ in the reticular dermis after in vivo exposure of human skin to material $1 .^{31}$ Thus, the in vitro method applied in the present study seems to be a good model for evaluating the penetration of inorganic particles through human skin.

In the present study, we encountered a large difference in the amount of silver present in the epidermis of the two donors. This was consistent for all three investigated materials, implying that these differences were dependent on the donor skin. One of the reasons might be higher abundance of hair in the donor skin with higher levels of silver in the dermis. The importance of hair follicles as a penetration route for solid particles (such as liposomes and nanoparticles) has been reported in literature. ${ }^{32}$ Baroli et al observed iron nanoparticles deposed below the viable epidermis and within and proximal to the hair follicles. ${ }^{33}$ However, the nanoparticles did not permeate through the skin. Moreover, Graf et al found that gold particles with dimensions of $161 \pm 13 \mathrm{~nm}$ were able to penetrate the superficial layers of the SC and hair follicles. ${ }^{34}$ Also in the study by Graf et al, no deeper penetration was observed. ${ }^{34}$ It was noted in the present study that silver-containing aggregates were localized not only in the vicinity of the hair but also in other areas (Figure 5).

For the health-risk assessment information on both, the extent of absorption and characterization of penetrated silver species are needed. In the present study, only the total amount of silver that penetrated into and across the skin could be determined. AFM and SEM analysis qualitatively provided the presence of silver particles in the skin; however, the relative composition of the silver species is not known. Furthermore, at present, there is a lack of reference exposure limits to silver nanoparticles.

It must be emphasized that penetration through the skin layers becomes more relevant in the presence of damaged skin, such as, for example, in the case of dermatitis or burns. A damaged skin barrier would not only increase the amount of silver that can penetrate across the skin but will likely enable penetration of larger nanoparticles. At present, there are only a few in vivo studies on silver uptake after the application of nanosilver textiles on damaged human skin. ${ }^{35-37}$

\section{Conclusion}

To our best knowledge, this is the first study to investigate both the extent of percutaneous penetration of silver and at the same time characterize the silver particles in different skin layers. The present study demonstrated that the use of silver-containing textiles leads to the release of silver and its penetration across the skin, implying that silver is systemically available. By using AFM and SEM-EDX, we showed 
the presence of silver particles of nano- and micro-size on the materials. We also identified silver-containing aggregates of micro-size in the epidermis and dermis, suggesting that these aggregates are formed in the skin, which is consistent with recent in vivo studies. Formation of these aggregates likely slow down systemic absorption of silver. On the other hand, these aggregates may form a reservoir, enabling prolonged release of silver ions, which might lead to local effects.

\section{Acknowledgments}

The authors would like to acknowledge the contribution of the COST Action Skin Barrier and Atopic Disease (SKINBAD). This work is partly funded by NanoNext.nl, a microand nanotechnology consortium of the Dutch Government and 130 partners.

\section{Disclosure}

The authors report no conflicts of interest in this work.

\section{References}

1. Cho KH, Park JE, Osaka T, Park SG. The study of antimicrobial activity and preservative effects of nanosilver ingredient. Electrochim Acta. 2005;51(5):956-960.

2. Sadeghi B, Garmaroudi FS, Hashemi M, et al. Comparison of the antibacterial activity on the nanosilver shapes: nanoparticles, nanorods and nanoplates. Adv Powder Technol. 2012;23(1):22-26.

3. Chen X, Schluesener HJ. Nanosilver: a nanoproduct in medical application. Toxicol Lett. 2008;176(1):1-12.

4. Simchi A, Tamjid E, Pishbin F, Boccaccini AR. Recent progress in inorganic and composite coatings with bactericidal capability for orthopaedic applications. Nanomedicine. 2011;7(1):22-39.

5. Larese FF, D'Agostin F, Crosera M, et al. Human skin penetration of silver nanoparticles through intact and damaged skin. Toxicology. 2009; 255(1-2):33-37.

6. Trop M, Novak M, Rodl S, Hellbom B, Kroell W, Goessler W. Silvercoating dressing acticoat caused raised liver enzymes and argyria-like symptoms in burn patient. J Trauma. 2006;60(3):648-652.

7. Wang XQ, Chang HE, Francis R, et al. Silver deposits in cutaneous burn scar tissue is a common phenomenon following application of a silver dressing. J Cutan Pathol. 2009;36(7):788-792.

8. Som C, Wick P, Krug H, Nowack B. Environmental and health effects of nanomaterials in nanotextiles and façade coatings. Environ Int. 2011; 37(6):1131-1142.

9. Samberg ME, Oldenburg SJ, Monteiro-Riviere NA. Evaluation of silver nanoparticle toxicity in skin in vivo and keratinocytes in vitro. Environ Health Perspect. 2010;118(3):407-413.

10. Benn T, Cavanagh B, Hristovski K, Posner JD, Westerhoff P. The release of nanosilver from consumer products used in the home. J Environ Qual. 2010;39(6):1875-1882.

11. Benn TM, Westerhoff P. Nanoparticle silver released into water from commercially available sock fabrics. Environ Sci Technol. 2008;42(11): 4133-4139.

12. Lorenz C, Windler L, von Goetz N, et al. Characterization of silver release from commercially available functional (nano)textiles. Chemosphere. 2012;89(7):817-824.

13. Pasricha A, Jangra SL, Singh N, et al. Comparative study of leaching of silver nanoparticles from fabric and effective effluent treatment. J Environ Sci. 2012;24(5):852-859.

14. Geranio L, Heuberger M, Nowack B. The behavior of silver nanotextiles during washing. Environ Sci Technol. 2009;43(21):8113-8118.
15. Farkas J, Peter H, Christian P, et al. Characterization of the effluent from a nanosilver producing washing machine. Environ Int. 2011;37(6): 1057-1062.

16. Impellitteri CA, Tolaymat TM, Scheckel KG. The speciation of silver nanoparticles in antimicrobial fabric before and after exposure to a hypochlorite/detergent solution. J Environ Qual. 2009;38(4):1528-1530.

17. Kulthong K, Srisung S, Boonpavanitchakul K, Kangwansupamonkon W, Maniratanachote R. Determination of silver nanoparticle release from antibacterial fabrics into artificial sweat. Part Fibre Toxicol. 2010;7:8.

18. Dunn K, Edward-Jones V. The role of Acticoat with nanocrystalline silver in the management of burns. Burns. 2004;30 Suppl 1:S1-S9.

19. Krieger BR, Davis DM, Sanchez JE, et al. The use of silver nylon in preventing surgical site infections following colon and rectal surgery. Dis Colon Rectum. 2011;54(8):1014-1019.

20. Silver S, Phung le T, Silver G. Silver as biocides in burn and wound dressings and bacterial resistance to silver compounds. J Ind Microbiol Biotechnol. 2006;33(7):627-634.

21. Castagnoli C, Alotto D, Cambieri I, et al. Evaluation of donor skin viability: fresh and cryopreserved skin using tetrazolium salt assay. Burns. 2003;29(8):759-767.

22. Bianco C, Adami G, Crosera M, et al. Silver percutaneous absorption after exposure to silver nanoparticles: a comparison study of three human skin graft samples used for clinical applications. Burns. 2014; 40(7):1390-1396.

23. Davies DJ, Ward RJ, Heylings JR. Multi-species assessment of electrical resistance as a skin integrity marker for in vitro percutaneous absorption studies. Toxicol In Vitro. 2004;18(3):351-358.

24. Franz TJ. Percutaneous absorption on the relevance of in vitro data. J Invest Dermatol. 1975;64(3):190-195.

25. Ražić SE, Čunko R, Svetličić V, Šegota S. Application of AFM for identification of fibre surface changes after plasma treatments. Mat Technol. 2011;26(3):146-152.

26. Rigo C, Roman M, Munivrana I, et al. Characterization and evaluation of silver release from four different dressings used in burns care. Burns. 2012;38(8):1131-1142.

27. von Goetz N, Lorenz C, Windler L, Nowack B, Heuberger M, Hungerbühler K. Migration of $\mathrm{Ag}$ - and $\mathrm{TiO}_{2}$-(nano)particles from textiles into artificial sweat under physical stress: experiments and exposure modeling. Environ Sci Technol. 2013;47(17):9979-9987.

28. Brett DW. A discussion of silver as an antimicrobial agent: alleviating the confusion. Ostomy Wound Manage. 2006;52(1):34-41.

29. Greulich C, Braun D, Peetsch A, et al. The toxic effect of silver ions and silver nanoparticles towards bacteria and human cells occurs in the same concentration range. RSC Adv. 2012;2:6981-6987.

30. van der Zande M, Vandebriel RJ, Van Doren E, et al. Distribution, elimination, and toxicity of silver nanoparticles and silver ions in rats after 28-day oral exposure. ACS Nano. 2012;6(8):7427-7442.

31. George R, Merten S, Wang TT, Kennedy P, Maitz P. In vivo analysis of dermal and systemic absorption of silver nanoparticles through healthy human skin. Australas J Dermatol. 2014;55(3):185-190.

32. Lane ME. Nanoparticles and the skin - applications and limitations. J Microencapsul. 2011;28(8):709-716.

33. Baroli B, Ennas MG, Loffredo F, Isola M, Pinna R, López-Quintela MA. Penetration of metallic nanoparticles in human full-thickness skin. J Invest Dermatol. 2007;127(7):1701-1712.

34. Graf C, Meinke M, Gao Q, et al. Qualitative detection of single submicron and nanoparticles in human skin by scanning transmission $\mathrm{x}$-ray microscopy. J Biomed Opt. 2009;14(2):021015.

35. Rigo C, Ferroni L, Tocco I, et al. Active silver nanoparticles for wound healing. Int J Mol Sci. 2013;14(3):4817-4840.

36. Moiemen NS, Shale E, Drysdale KJ, Smith G, Wilson YT, Papini R. Acticoat dressings and major burns: systemic silver absorption. Burns. 2011; 37(1):27-35.

37. Vlachou E, Chipp E, Shale E, Wilson YT, Papini R, Moiemen NS. The safety of nanocrystalline silver dressings on burns: a study of systemic silver absorption. Burns. 2007;33(8):979-985. 


\section{Publish your work in this journal}

The International Journal of Nanomedicine is an international, peerreviewed journal focusing on the application of nanotechnology in diagnostics, therapeutics, and drug delivery systems throughout the biomedical field. This journal is indexed on PubMed Central,

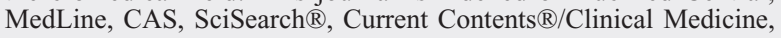

Journal Citation Reports/Science Edition, EMBase, Scopus and the Elsevier Bibliographic databases. The manuscript management system is completely online and includes a very quick and fair peer-review system, which is all easy to use. Visit http://www.dovepress.com/ testimonials.php to read real quotes from published authors.

Submit your manuscript here: http://www.dovepress.com/international-journal-of-nanomedicine-journal 